\title{
A Case Report on Leech Infestation as a Cause of Severe Anemia in a 10-Month-Old Infant in Ethiopia
}

This article was published in the following Dove Press journal: International Medical Case Reports Journal

\author{
Amsalu Molla Getahun' \\ Yichalal Endayehu ${ }^{2}$ \\ Gebrie Dinkayehu Berhanu' \\ 'Department of Surgery, School of \\ Medicine, College of Health Sciences, \\ Debre Tabor University, Debre Tabor, \\ Amhara Regional State, Ethiopia; \\ ${ }^{2}$ Department of Pediatrics and Child \\ Health, School of Medicine, College of \\ Health Sciences, Debre Tabor University, \\ Debre Tabor, Amhara Regional State, \\ Ethiopia
}

Background: Leeches are blood sucking hermaphroditic parasites belonged to the phylum Annelida of the class Hirudinea. Based on the location of leech infestation, the patient may present with anemia and respiratory symptoms. Even though Leech infestation is mentioned as common problem in African countries and the common cause of anemia, especially in children but it is not mentioned as a cause of severe anemia in an infant.

Case Presentation: In this paper, we are reporting a 10 months old baby presented to Debre Tabor General Hospital with nasal bleeding and blood tingled vomiting of four days duration. With the diagnosis of severe anemia secondary to leech infestation, she was transfused with $360 \mathrm{~mL}$ of whole blood and the leech was removed from the oropharynx with McGill forceps. She was followed for 48 hours. There was no ongoing bleeding; the vital signs became stable, and then patient's parents were advised to boil drinking water before use. Finally, the infant discharged with improvement.

Conclusion and Recommendation: We concluded that leech infestation should be included as the differential diagnosis of an infant presented with nasal bleeding and blood tingled vomiting who came from rural areas.

Keywords: leech, epistaxis, hematemesis, severe anemia, infant, Ethiopia

\section{Background}

Leeches are blood sucking hermaphroditic parasites belonged to the phylum Annelida of the class Hirudinea. Leeches that attack humans are alienated into two classes; land leeches, which have powerful jaws that can penetrate the skin so that they can attach anywhere on the external surface of the body, and aquatic leeches, which have weak jaws and require soft tissues to feed on. ${ }^{1}$

Infestation with leeches can occur from drinking unsafe water or swimming from contaminated water sources which can lead to several complications in the aero-digestive tract. Epistaxis, hematemesis, melena, and foreign body sensation are common presenting symptoms of leech infestation. It occurs in the body of children including pharynx, nose and esophagus, bowel, and, seldom, the vagina and vulva. $^{2-11}$ There are reports on leech infestation in different sites of the body and most of them are beyond the age of one.

Depending on the site of leech the patient may present with bleeding and respiratory symptoms, in severe cases, it may cause fatalities especially in children. In this paper, we are reporting an unusual cause of severe anemia in a 10 months old female infant caused by oropharyngeal leech infestation.
Correspondence: Amsalu Molla Getahun Email dramsalu@gmail.com

International Medical Case Reports Journal 202I:|4 III-I|4 


\section{Case Presentation}

A10 month's old female infant from Farta Woreda was brought by her parents on Nov 5, 2018 to the Under-five Outpatient Department of Debre Tabor General Hospital, Debre Tabor, Ethiopia. The infant presented with nasal bleeding and blood tingled vomiting of four days duration. She also had associated cough and High-grade intermittent fever (HGIF). She had no previous history of similar problems, no travel history, no bleeding disorder in the family, and she was fully vaccinated for her age. The source of drinking water was from the river. On physical examination, she was acute sick looking with vital signs of Pulse Rate $(\mathrm{PR})=154$ Beats per Minute (bpm), feeble, Respiratory Rate $(\mathrm{RR})=40$ per $\min \mathrm{T}^{\circ}=36.7^{\circ} \mathrm{c}$.

On HEENT: She had pale conjunctiva, non-icteric sclera, blood stained nose and mouth, and on spatula examination clotted blood on the oropharynx. On the integumentary system, she had severe palmar pallor, no ecchymosis. She was lethargic. With the assessment of hypovolemic shock plus severe anemia secondary to acute blood loss secondary to leech infestation rule out severe malaria. She was investigated and the results were Hemoglobin (HGB) $3 \mathrm{mg} / \mathrm{dl}$, Blood group and Rhesus Factor $(\mathrm{RH})=\mathrm{O}^{+}$, Blood Film was negative for hemo-parasite, Random Blood Sugar $($ RBS $)=157 \mathrm{mg} / \mathrm{dl}$. She was resuscitated with $20 \mathrm{~mL} / \mathrm{kg}$ of normal saline fast and then cross-matched blood transfusion started $20 \mathrm{~mL} / \mathrm{kg}$ ( $180 \mathrm{~mL}$ of whole blood) given in $3 \mathrm{hrs}$ with $1 \mathrm{mg} / \mathrm{kg}$ of Lasix given pre- and post-transfusion and she was taken to the OR and in the OR under general anesthesia with laryngoscopy and McGill forceps dark brown leech was removed from the oropharynx (Figure 1). On Nov 6 her vital signs were PR- 120bpm and $\mathrm{T}^{\circ}-36.5^{\circ} \mathrm{c}$ RR-32 and Post-procedure hemoglobin was repeated and it was $7.5 \mathrm{mg} / \mathrm{dl}$. She was again transfused with $20 \mathrm{~mL} / \mathrm{kg}$ (180 mL of whole blood) cross-matched blood over $3 \mathrm{hrs}$ and finally, hemoglobin becomes $11 \mathrm{mg} / \mathrm{dl}$ and the patient was followed for 48 hours and there was no bleeding, the vital signs became stable and the child also became alert. The patient's parents were advised to boil drinking water before use. Finally, the infant discharged with improvement.

\section{Discussion and Conclusions}

As leeches can consume human blood equivalent to $890 \%$ of their body weight, they can cause severe anemia and as a result blood transfusion may be required. ${ }^{12-14}$ As Jafari Rouhietal reported, a 9-month infant with the diagnosis of

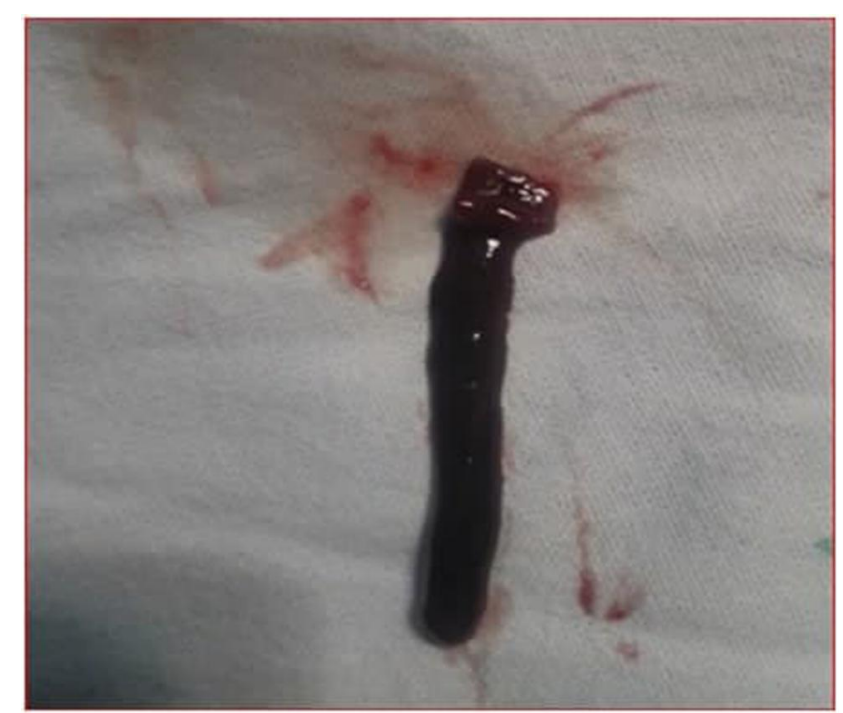

Figure I The leech removed from oropharynx of 10 months infant at Debre Tabor General Hospital, 2018.

nasopharyngeal leech infestation presented with epistaxis and hematemesis. ${ }^{15}$ Bleeding may persist due to anticoagulants in the saliva of the leech such as hirudin, which inhibits thrombin, factor IXa, hementerin, and a plasminogen activator. ${ }^{16-18}$

The most frequent complaints of leech infestations were bleeding from the site where leeches attach to. As Agin et al reported nasopharyngeal leech infestation was presented with epistaxis and hematemesis. ${ }^{14}$ And also, Ghimire and Acharya reported unilateral nostril epistaxis caused by leech infestation. ${ }^{19}$ Estambalel et al also reported hematemesis and severe anemia due to a pharyngeal leech in a Kenyan child ${ }^{20}$ and vaginal bleeding has also been reported in a 50 years old Ethiopian woman after menopause due to leech infestation. ${ }^{21}$

Mekonnen, D., has also reported that blood-stained saliva and shortness of breath were the presenting complaints in a 7years old Ethiopian child due to leech infestation. ${ }^{22}$ As Kantakin et al reported leech infestation as an unusual cause of bleeding on the floor of the mouth in a 10 years old turkey child. ${ }^{23}$ Tabook, et al, also reported nasopharyngeal leech infestation with dry cough and spitting of blood. ${ }^{8}$ Shane Duffy also reported that melena and hematemesis were the presenting compliant in 2 years old Ethiopian child with severe anemia secondary to leech infestation. ${ }^{24}$ In our case of nasopharyngeal leech infestation with epistaxis and hematemesis were the symptoms mentioned by the patient family.

Removal of leeches from the surface areas can be assisted by the application of alcohol salt, vinegar, or 
a flame to the leech. Internally attached leeches may detach on exposure to gurgled saline or may be removed by forceps. Hemorrhage due to leech bite is best managed by removing it following which, the bleeding stops spontaneously in almost all cases. Profuse bleeding may lead to hypotension and anemia which may necessitate blood transfusion. In our case, the leech was removed gently via McGill forceps and the bleeding stops spontaneously and the patient was transfused with $360 \mathrm{~mL}$ of whole blood and discharged after 48 hours follow up. On follow up the patient became stable and alert with HGB of $11 \mathrm{~g} / \mathrm{dl}$.

In conclusion, leech infestation should be kept in mind as a differential diagnosis of severe anemia in infants with epistaxis and hematemesis. The provision of clean water in rural areas and encouraging villagers to drink boiled and filtered water is very critical. Avoid swimming in leech endemic areas can also have paramount effect to prevent leech bites. Assessment of drinking water is also very important.

\section{Abbreviations}

FB, foreign body; Hgb, hemoglobin; HGIF, high-grade intermittent fever; OR, operation room; PR, pulse rate; RBS, random blood sugar; $\mathrm{RH}$, rhesus factor; RR, respiratory rate; $\mathrm{T}^{\circ}$, temperature.

\section{Ethical Clearance}

We have obtained ethical clearance letter from Debre Tabor University Ethical Review Committee. Written informed consent was obtained from the infant's mother. The name of the patient was not stated for the assurance of confidentiality.

\section{Consent for Publication}

Written informed consent was obtained from the infant's parent (mother) for publication of this case report and any accompanying images. A copy of the written consent is available and we can convey at any time when necessary.

\section{Acknowledgment}

We would like to express our deepest gratitude for the patient and patient's family.

\section{Author Contributions}

All authors made substantial contributions to conception and design, acquisition of data, or analysis and interpretation of data; took part in drafting the article or revising it critically for important intellectual content; agreed to submit to the current journal; gave final approval of the version to be published; and agree to be accountable for all aspects of the work.

\section{Funding}

There is no funding to report.

\section{Disclosure}

The authors report no conflicts of interest for this work.

\section{References}

1. Sivachandran P, Heera R, Lalitha P, et al. An overview of leech and its therapeutic applications. J Coast Life Med. 2015;3(5):405-413.

2. Ghazzawi I, Zuraiqat F, Burqan O. Leech infestation causing upper gastrointestinal; 2004:5-7.

3. Peleg R, Shvartzman P. Case report: cutaneous nerve entrapment. Abdominal wall pain in an elderly patient. Can Fam Physician. 2001;47(10):788-789.

4. Arvinder Singh HS. Abnormal per rectal bleed. Scott Med J. 2011;56 (1):2010-2012.

5. Krüger C, Malleyeck I, Olsen OHE. Aquatic leech infestation: a rare cause of severe anaemia in an adolescent Tanzanian girl. Eur J Pediatr. 2004;163(6):297-299. doi:10.1007/s00431-004-1422-0

6. Zengin Y, Gunduz E, Icer M, et al. A rare cause of epistaxis due to Leech infestation: a case report. J Acad Emerg Med Case Rep. 2014;5 (7):197-199. doi:10.5152/jaemcr.2014.181

7. Basu S, Chandra PK, Basu S. A leech in the large bowel. $J$ R Soc Med. 2004;97(2):83. doi:10.1177/014107680409700213

8. Tabook SMS, Tawab HMA. A leech in the nasopharynx of a child: a case report. IJSS Case Rep Rev. 2015;1(9):35-37.

9. June A, Ashraf M. Original article infestation in respiratory tract (URT). Med Channel. 2013;19(2):60-62.

10. Moslehi MA, Imanieh MH, Adib A. Bronchial leech infestation in a 15-year-old female. Case Rep Pediatr. 2016;2016(Figure 2):1-4. doi:10.1155/2016/2372686

11. Shitaye N, Shibabaw S. Severe anemia due to pharyngeal leech infestation; a case report from Ethiopia. BMC Surg. 2017;17(1):1-3. doi:10.1186/s12893-017-0298-7

12. Aversa M, Bhinder S, Tanguay J, Thenganatt J. A rare cause of hemoptysis. Respir Med Case Rep. 2014;13:48-50.

13. Oğhan F, Güvey A, Özkiriş M, Gülcan E. Oropharyngeal leech infestation and therapeutic options. Turkiye Parazitol Derg. 2010;34(4):200-202.

14. Ağin H, Ayhan FY, Gülfidan G, Cevik D, Derebaşi H. Severe anemia due to the pharyngeal leech Limnatisnilotica in a child. Turkish Soc Parasitol. 2008;32(3):247-248.

15. Vegari S, Ghaffarlou M, Davarimajd L, Golzari SE. Globus sensation due to a mobile foreign body in a 41-year-old female. J Cardiovasc Thorac Res. 2012;4(1):29-30. doi:10.5681/jcvtr.2012.007

16. Mory RN, Mindell D, Bloom DA. The leech and the physician: biology, etymology, and medical practice with Hirudineamedicinalis. World J Surg. 2000;24(7):878-883. doi:10.1007/s002680010141

17. Leoncini E, Ricciardi W, Cadoni G, et al. Adult height and head and neck cancer: a pooled analysis within the INHANCE Consortium. Head Neck. 2014;36(10):1391.

18. Yelken MK, Okur MH, Yuca SA. Leech infestation of the nasopharynx; a rare cause of epistaxis and hemorrhage. Eur J Gen Med. 2011;8(2):141-143.

19. Ghimire A, Acharya A. Unusual cause of unilateral epistaxis: nasal leech infestation. J Nepal Med Assoc. 2008;47(169):38-40.

20. Estambale BBA, Knight R, Chunge R. Haematemesis and severe anaemia due to a pharyngeal leech (myxobdellaafricana) in a Kenyan child: a case report. Trans R Soc Trop Med Hyg. 1992;86 (4):458. doi:10.1016/0035-9203(92)90271-D 
21. Mekasha A. Postmenopausal vaginal bleeding due to vaginal wall leech infestation. Ethiop Med J. 1995;33:271.

22. Mekonnen D. Leech infestation: the unusual cause of upper airway obstruction. Ethiop J Health Sci. 2013;23(1):65-68.

23. Kantekin Y, Sarı K, Özkırış M, KapusuzGencer Z. An unusual cause of bleeding on the floor of mouth: leech infestation. Turkiye Parazitol Derg. 2015;39(4):323-325. doi:10.5152/tpd.2015.4254
24. Duffy S. A case series of bleeding due to leech infestation from the Gimbie region, Ethiopia. Trop Doct. 2008;38(1):58-59. doi:10.1258/ td.2007.060162

\section{Publish your work in this journal}

The International Medical Case Reports Journal is an international, peer-reviewed open-access journal publishing original case reports from all medical specialties. Previously unpublished medical posters are also accepted relating to any area of clinical or preclinical science. Submissions should not normally exceed 2,000 words or 4 published pages including figures, diagrams and references. The manuscript management system is completely online and includes a very quick and fair peer-review system, which is all easy to use. Visit http://www.dovepress.com/testimonials.php to read real quotes from published authors. 